\title{
L'EXPERIÈNCIA DELS DARRERS VINT ANYS: UNA ANÀLISI COMPARATIVA DE LES CERIMONIES OLIMMPIQUES*
}

\author{
John MacAloon \\ The University of Chicago
}

Resum

Des d'una aproximacio antropologica, l'article presenta una reflexió sobre el significat cultural de les cerimònies d'obertura i clausura dels jocs Olimpics. Les cerimònies olimpiques són un escenari privilegiat per analitzar els processos d'intercanvi cultural que es donen a nivell internacional. En aquest sentit, l'autor elabora un model comparatiu que permet analitzar les diferències culturals que apareixen en ambdues celebracions olimpiques. En aquesta pers. pectiva, els jocs Olimpics s'entenen com un sistema de representacio múltiple que incorpora elements de ritual, joc, festival i espectacle. De totes aquestes categories, l'autor escull la de festival per posar en pràctica el setu model comparatiu, ja que aquesta contempla els elements clau de diversió, democràcia, igualitarisme i participació, cabdals per evidenciar les diferències culturals.

L'autor compara críticament les cerimònies de Los Angeles $i$ Seül, i dóna algunes indicacions del que pot succeir a Barcelona. Les cerimònies dels Jocs Olimpics de 1992 s'enfronten al repte de representar el nou ordre mundial $i$ el paper d'Espanya dins d'una Europa unida, axí com també les relacions que existeixen entre l'Estat espanyol, Catalunya i Barcelona.

Resumen

Desde una aproximación antropológica, el articulo presenta una reflexión sobre el significado cultural de los /uegos Olimpicos. Las ceremonias olimpicas son un escenario de privilegiado para analizar los procesos de intercambio cultural que se dan a nivel internacional. En este sentido, el autor elabora un modelo comparativo que permite analizar las diferencias culturales que aparecen en ambas celebraciones olimpicas. Bajo esta vision los Juegos se entienden como un sistema de representación múltiple que incorpora elementos de ritual, juego, festival y espectáculo. De todas estas categorias el autor escoge la de festival para poner en práctica su modelo comparativo, ya que esta contempla

* Traducció de Elisabeth Tejero de la ponencia presentada al Simposi Internacional sobre Jocs Olimpics, comunicació i Intervanvis culturals. 
"Papers»: Revista de Sociologia

los elementos clave de diversion, democracia, igualitarismo y participación, centrales para evidenciar las diferencias culturales.

El autor compara criticamente las ceremonias de los Angeles y Seúl, dando algunas indicaciones sobre lo que puede suceder en Barcelona. Las ceremonias de los Juegos Olimpicos de 1992 se enfrentan al reto de representar el nuevo orden mundial y el papel de España en una Europa unida, asi como la relación que existe entre el Estado español, Cataluña y Barcelona.

Abstract

From an antropological point of view, the article presents a reflection on the cultural significance of the Olympic Games. The olimpic ceremonies ara a privilaged scene in which to andyse the process of cultural exchange at an international level. In this sense, the author expands a comparative model which allows the analizise of the different cultures which appear at both olympic ceremonies. With this in mind, the olympics can be undesrtood as a system of multiple representation which incorporates elements of ritual, sport, festival ans spectacle. From all this categories the author chooses that of festival with which to develop his comparative model, having already discussed the key elements of diversions, democracy, egalitarianism and participation, essential in order to overcome the cultural differences.

The author critically compares the ceremonies of Los Angeles and Seul, giving some indications on what could happen in Barcelona. The olympic ceremonies of 1992 face the task of representing the new world order and the position of Spain in a United Europe, aswell as the relation between the spanish State, Catalonia and Barcelona.

Ja al 1910 Pierre de Coubertin va entendre que era en les cerimònies d'obertura i clausura on l'Olimpiada es distingia del que podia ser un campionat mundial. Les cerimònies tenen la responsabilitar de representar el que Coubertin va descriure com "l'essència i la qualitat de l'olimpisme que es diferencia del simple atletisme al qual engloba i sobrepassa». Avui podem apreciar la realitat de les seves paraules: d'una banda, pel fet que cap altre campionat, ni tan sols els campionats mundials, no ha desenvolupat una cerimònia evocativa $i$, d'altra banda, en altres esdeveniments esportius no té lloc una difusió tan massiva i a preu tan elevat com la que es dóna en les cerimònies d'obertura i clausura dels Jocs Olímpics.

A Seül, per exemple, més de 300.000 coreans van seguir en directe l'assaig final de la cerimònia d'obertura, i milers ho van fer per televisió, de fet les entrades de l'obertura van anar a la revenda a més de 8.000 dòlars. L'enorme audiència mundial que va veure per televisió aquestes cerimònies, probablement va ser la més gran concentració d'atenció global en la història humana, $i$ en moltes parts del món aquestes cerimònies apareixen com l'esdeveniment 
més recordat i discutit de la representació dels Jocs Olfmpics de Seül. Podem pensar que durant els Jocs Olímpics de Barcelona succeïrà probablement el mateix.

L'audiència mundial està esperant la competició esportiva i altres tipus de representacions olímpiques, però les més esperades, examinades i avaluades seran les cerimònies d'obertura $\mathrm{i}$ clausura. Les cerimònies representen doncs, segons alguns punts de vista, el repte més significatiu que afronta el COOB.

\section{PER QUE SON TAN IMPORTANTS LES CERIMÒNIES?}

Algunes de les raons de la importància de les cerimònies olimpiques són força clares. En el pla estètic - ritualització de l'espai, del temps i de l'atenció- aquestes representacions, a les quals es dóna una atenció especial, marquen l'obertura i la clausura del temps olímpic. Per la resta del període olímpic, l'atenció es dilueix entre molts esports i esdeveniments esportius com són ara els lliuraments de premis. A Barcelona, tant la gent de la pròpia ciutat, com els visitants olimpics i els mitjans de comunicació, podran parar atencio a un gran nombre de fets paral.fels als jocs, com són la vida de la ciuttat $\mathrm{i}$ 'els festivals artístics i populars. Un esdeveniment esportiut especialment significatiu o determinats episodis polítics poden donar a conèixer un conjunt de pä́sos i regions, però serà només en les cerimònies d'obertura i clausura on es transmet la força psicològica de participar en un esdeveniment juntament amb el món. Aquesta potser és la percepció fenomenològica més propera que encara es coneix pel que Marx va denominar "l'ésser de l'espècien.

La segona raó important apareix en el pla de la representació nacional. Ciutadans dels päsos del nord ric deuen enrecordar-se que només al voltant del $25 \%$ de les nacions participants en els Jocs Olimpics tindran un atleta guanyador d'una medalla, és a dir, veuran hissar la seva bandera o sentiran el seu himne durant el transcurs dels Jocs. En el que és pròpiament l'esport, aquestes nacions eliminades es tornen invisibles. En les cerimònies d'obertura, contràriament, totes les nacions són, si més no des d'un punt de vista formal, iguals. Amb l'excepció de la nació amfitriona, són presentades amb la mateixa visibilitat, amb igualtat de valors, en definitiva, sota la igualtat "olímpica». De fet, per la majoria de les nacions participants la desfilada general, entesa com una desfilada de països entre països, és el més important. Durant alguns moments, encara que siguin curts, les nacions que es reconeixen com pobres i periferiques des de la perspectiva del poder mundial, apareixen en el centre de l'atenció del món. 
El tercer factor més important de les cerimònies el trobem en el pla de les relacions sociològiques $\mathrm{i}$ interculturals. Les cerimònies d'obertura i clausura són els moments centrals en els quals les representacions olímpiques d'humanitarisme són transformades en relacions d’integració i també de diferenciació respecte al país i la ciutat amfitriona. El sentit d'aquestes cerimònies està fixat pel COI. Les opcions que té el Comitè Organitzador per fer tradicionals aquests signes rituals i utilitzar-los com a simbols de valors, intencions i creativitat, són limitades. Per exemple, escollir la música per a la desfilada de les nacions i de l'entrada de la torxa olimpica, la identitat de l'últim relleu per introduir-la dins l'estadi i el significat de com s'encén el calderó olímpic. La resta de les cerimònies d'obertura i clausura, les que fan referència a cerimònies no oficials o manifestacions culturals, estan quasi completament obertes a la discreció i a la innovació del Comitè Organitzador. Les audiències d'ambdós tipus de representacions i la tradició olímpica esperen una representació evocativa de la cultura de la nació amfitriona, creada per escenògrafs $\mathrm{i}$ arristes locals o nacionals.

Bilions de persones entenen aquestes representacions tal com els següents textos indiquen:

1. què és allò que la ciutat i la nació amfitriona més desitja comunicar de si mateixa a la resta del món;

2. com aquestes entenen la relació entre la pròpia cultura i la universalització de les lógiques aspiracions del moviment olímpic;

3. quanta inversió d'energia i imaginació s'han dedicat als Jocs Olímpics per part del pás amfitrió $i$, en el cas de les cerimònies d'obertura, quant èxit tenen en el seu conjunt $o$, en tot cas, quant èxit haurien de tenir.

\section{LA DOBLE VESSANT DELS DISSENYS DE LES CERIMONIES OLIMPIQUES}

Els dissenyadors del Comitè Organitzador, escenògrafs, coreògrafs, compositors, directors musicals, i els modistes han de fer front a la seva tasca en un doble camp. Per un costat, han de conceptualitzar i produir el programa d'acord amb les intencions de la cultura local, les seves tradicions i invencions. Per un altre costat, han de treballar per assegurar que aquestes intencions i significats siguin adequadament comunicats a la gran audiència a través de diversos mitjans de comunicació mundials. La principal activitat, la producció de la cultura, inclou el dificil projecte de construir una visió teatral de la vida local i nacional fidel a la pròpia cultura $i$ adient a l'esperit de l'ocasió olímpica. Ambdues qüestions han d'estar representades de manera prou 
simple $i$ ressonant per atreure $i$ satisfer les audiències de les nacions convidades. La segona activitat, la comunicació de la cultura, requereix la consideració d'alguns estereotips i de concepcions estrangeres que haurien de evitar els mals entesos o fins $i$ tot d'allo que pugui significar una ofensa per a algun país. Les intencions culturals de les cerimònies han de ser tradur̈des en imatges escrites, documents, premsa, $\mathrm{i}$ altres materials exegètics en llengua estrangera pels periodistes d'altres pä̈sos. A més, es necessiten activitats educatives orientades a garantir que els mitjans de comunicació foranis entenguin $i$ confïn en les informacions que distribueix el Comitè Organitzador que han de ser difoses a la resta del món.

Investigacions comparatives entorn de les diferents retransmissions internacionals de les cerimonies olímpiques han mostrat el que està en joc en aquesta última tasca i com n'és de complicada. En el cas de Los Angeles el 1984, cas que jo analitzo en aquest article, els responsables del Comitè Organitzador no varen dedicar prou atenció a allò que els periodistes internacionals i el públic podria pensar i dir sobre aquestes cerimònies. Van creure estúpidament que la seva producció d'intencions i símbols seria transparentment unívoca i no controvertida per l'audiència no-nord-americana. Els responsables del Comitè Organitzador de Los Angeles no estaven preparats per rebre tantes crítiques ni perquè apareguéssin tants malentesos interculturals, com els que van tenir lloc. Corea, però, és un cas força diferent, en bona part perquè els organitzadors de les cerimònies del Comitè Organitzador de Seül es van preocupar molt que els estrangers entenguessin el seu missatge i no hi haguessin malentesos. Malgrat la brillant concepció de les cerimònies d'obertura i clausura - riques en significats culturals coreans i de l'est d'Àsia; organitzades amb intencions unificades i de facil comprensió narrativa; producte de sis anys de treball realitzat per més de mil dels més distingits acadèmics i artistes coreans; acompanyats d'un meravellós escenari d'igualtat molt instructiu pels mitjans de comunicació- moltes agències d'informació occidental varen fer pocs esforços per comunicar les intencions dels dissenyadors organitzadors de Seül.

\section{L'ESTUDI COMPARATIU DE LES CERIMONIES OLIMPIQUES}

Durant quasi quinze anys he estat dedicat al desenvolupament de models analítics i de llenguatges, per comparar sistemàticament les representacions culturals olímpiques en diferents contextos culturals. La intenció d'aquesta investigació és adquirir una nova i més concentrada comprensió del procés d'intercanvi cultural en el sistema contemporani global, pel qual, les cerimònies olímpiques són un bon laboratori. Aquest treball ha tingut un gran in- 
terès pels productors de les cerimònies perquè el model es redueix a unes proporcions $i$ concepcions força operatives. Analitzar les cerimonies passades ha proporcionat, de manera retrospectiva, un conjunt de consideracions i punts clau que els dissenyadors de futures cerimònies poden ara identificar amb antelació.

Les decisions que els organitzadors prenen permeten analitzar les cerimònies a partir d'un sistema comparatiu que ajuda els antropòlegs a desxifrar les estructures culturals que es prioritzen, així com el lloc de la cultura local en el repertori global.

En aquest article considero quatre qüestions importants:

1. Quin tipus de representacíb cultural consideren els organitzadors que produeixen quan fan l'obertura i la clausura dels Jocs Olímpics? Un programa televisiz? Un festival cultural o un espectacle folklòric? Un ritual religiós, cosmològic o sociologic? Un joc o un esdeveniment esportiu?

2. Quina és la lògica social de les representacions que ells produeixen? De la ideologia olímpica i la tradició en resulten tres categories d'identitat: la humanitat, la nació i la persona individual. Com trien els organitzadors aquestes categories en el pla internacional i respecte a la seva pròpia societat? Quines identitats locals i de la resta de nacions participants estan determinades a ser explícitament o implícitament recollides en aquestes representacions?

3. Quina actitud general tenen els dissenyadors de les cerimònies sobre la categoria d'allò "polític"? Persegueixen l'harmonia olímpica suprimint totes les representacions de tensions locals, regionals, nacionals $\mathrm{i}$ internacionals? O persegueixen incorporar clarament una visió realista d'aquests conflictes?

4. Com es veuen els dissenyadors i organitzadors de les cerimónies: com a productors d'una obra d'art de significació històrica que inspirarà una continuada contemplacio, reflexió i comentaris temps després que els Jocs Olímpics hagin finalitzat? O veuen la seva feina com a una producció passatgera, com a una experiència on l'avaluació depèn solament de la seva efecrivitat en el moment dels Jocs?

Faré un repàs de les respostes que els organitzadors dels jocs Olímpics de Los Angeles han donat en aquest seguit de qüestions. Això ens permetrà comparar les decisions que han estat preses en anteriors edicions dels Jocs Olimpics i, així mateix, fer una aproximació a les que en aquests moments està prenent el $\mathrm{COOB}$. Però abans d'elaborar alguns dels models que han fet possible la comparacio, cal que situi els pressupostos intel.lectuals en els quals fonamento la meva investigació.

L'anàlisi que aquí presento està basada en una tècnica etrogràfica teòricament constituida per un concepte de cultura antropològic i semiològic, 
que inclou discursos interculturals meta-lingüístics i meta-comunicatius. Com molts antropòlegs culturals americans, parteixo del relativisme cultural estudiant allò que està a la base dels aspectes comuns interculturals. Realment, he tractat de situar la meva antropologia dels Jocs Olímpics i del Moviment Olimpic des d'una perspectiva bastant alternativa a les de l'humanisme universal europeu, del racionalisme liberal i del neo-marxisme que han dominat els centres tradicionals de producció i de crítica.

Però com a simple etnòleg, la meva aproximació no ha estat tant generar una concepció de l'olimpisme, com un intent pràctic d'entendre el fenomen en si mateix. A diverses parts del món avui, l'humanisme universal, l'economia política liberal, i el marxisme són vistos com a simples facetes de la mateixa "pedra filosofal" d'occident, per això, moltes persones dels bilions que segueixen les cerimònies olimpiques les interpreten a partir d'uns criteris euroamericans que són els que dominen aquest esdeveniment. Els conceptes de modernització, occidentalització, industrialització, civilització, racionalització, s'han estès a Europa i al Tercer Món. Però aquests conceptes no poden explicar l'enorme atencío multicultural que desperten els Jocs Olímpics. En la pràctica, les olimpíades són un fenomen global, en la teoria popular, les Olimpíades són en tots el líocs un fenomen "parroquial". La tasca de l'antropologia olímpica és, aleshores, no substituir una teoria professional de la ciència social per una popular, sinó generar models per comprendre la pluralitat real de les antropologies populars, que ja presenten $i$ configuren els Jocs com a un fenomen d'interès i poder global.

\section{ELS JOCS OLIMPICS COM UN SISTEMA DE REPRESENTACIO CONCENTRAT I DIVERSIFICAT}

Qualsevol model comparatiu perquè serveixi ha de tenir en compte el fet que els Jocs Olímpics són un sistema de representació complex, concentrat: dins d'un altre fenomen total que és l'Olimplada la qual s'expansiona en direccions diferents $\mathrm{i}$ amb intensitat diversa per interactuar en els contextos culturals on tenen lloc les representacions. De manera més simple, els Jocs Olímpics incorporen rituals, jocs, festivals, espectacles i depenen del poder semàntic i evocatiu d'aquesta multiplicitat de gèneres. Com jo deia al principi, per exemple, si no hi hagués cerimònia d'obertura i clatusura, els Jocs Olfmpics no serien els Jocs Olimpics, com a molt serien uns campionats mundials de molts esports. Així doncs, qualsevol intent de discutir i analitzar el conjunt del Jocs exclusivament en termes de categories logiques i valors dels "esports» i els "jocs" està condemnat a fracassar. De la mateixa manera, qualsevol intent d'entendre els Jocs Olímpics sota la categoria de fenomen 
per a la comunicació de masses o d'espectacle polític — com és el cas de la crítica neo-marxista i la dels acadèmics de la comunicació- garanteix també el fracas. Coneixem els intents de sociòlegs, antropolegs i religiosos per entendre el conjunt de l'esdeveniment en termes d'un genèric "procés ritual", o dels historiadors culturals, folkloristes, estilistes que pretenen reduir els jocs a festivals artístics o exhibicions internacionals, al marge de qualsevol relací amb el país on es realitza. Un model general del sistema de representació olímpica té en compte les diferents contribucions d'aquests discursos, precisament per refusar l'hegemonia de qualsevol d'ells, atesa la incertesa de l'objecte d'estudi que hi ha al darrera. Estendre el que hi ha d'unitari sota el fenomen de "les Olimpíades" només pot fer-se a través d'un sistema complex de relacions entre moltes i diverses formes representatives amb diferents capacitats humanes de representar, celebrar i consagrar.

En segon lloc, qualsevol model ha d'entendre que les categories de "jocs", "rite", "festival» $i$ "espectacle» no denoten ni connoten el mateix per a les 167 nacions olímpiques, ni per a les incomptables formacions culturals subnacionals, ni per a les més de 3.000 llengües mundials. A més, tampoc no existeixen universals com a categories. El model de les relacions lògiques $\mathrm{i}$ semàntiques deu ésser construît de tal manera que faci evident tant allò inadequat com allo adequat en la seva adaptació a la cultura local i també en l'adaptació amb les cultures locals mundials. Un bon model serà aquell que superi les diferències en la traducció cultural de les diferents categories.

En tercer lloc, des d'un punt de vista semiotic, s'ha de construir un model de sistema olímpic on la comunicació humana està formada no sols per missatges implícits sinó també per meta-missatges, és a dir, missatges de com entendre els missatges. Jo defenso que categories i tipificacions com "això és un ritual» o «això és un esdeveniment publicitari» són meta-missatges. El sistema de representació olímpica, per tant, és una interacció complexa de valors i de meta-comunicacions que tenen diferent importància, relacions jeràrquiques i diferent poder semàntic segons les diverses cultures i les seves diferents expressions en els Jocs Olímpics. Si deixem de banda aquesta construcció meta-comunicativa, amb les seves situacions tenses, conflictives i amb les seves complementarietats, s'està afavorint que allò que es vol comunicar tant per part dels "actors olímpics" com per part de les audiències no sigui adequadament entes i interpretat. Malauradament, molts dels comentaris occidentals sobre les representacions olímpiques són reduits al simple pragmatisme occidental, deixant de banda el simbolisme i els valors referencials que es representen a les cerimònies olímpiques. El funcionalisme apareix com el discurs analític dominant tant en el pla acadèmic com en el pla popular.

Les correspondències que puguin establir-se entre els gèneres d'espectacle, de programa televisiu, de festival, d'escenes populars al carrer o festes a les 
residències dels atletes, entre els rites d'obertura, victòria i clausura de les cerimònies, i entre el joc i l'esdeveniment esportiu, són suficients per trobar interessants comparacions entre Jocs Olímpics. Però el model és capaç de trobar elements més subtils per comparar lés diferents experiències olímpiques.

Quan es volen fer desaparèixer les diferències culturals entre els països "olímpics", surten a la llum les discrepàncies o disfuncionalitats que poden guiar les nostres investigacions. Aquestes diferències són presents fins i tot entte llengües amb forces similituds. El contrast pot ésser encara més marcat amb les llengües no occidentals on les similituds dels significats són encara menys clares.

Les mateixes investigacions heuristiques es plantejaran als Jocs Olímpics de Barcelona quan s'hagi d'adaptar els gèneres d'espectacle, ritual, joc i festival al castellà, català i llengües amb aparents similituds.

El model també ens permet aportar una sistemàtica relació dels diferents aspectes del festival que normalment no són analitzats i comentats com, per exemple, el relleu de la torxa olfmpica, o la vida a la vila dels atletes, així com reconèixer molts aspectes de la construcció abstracta i unfvoca de la cerimònia d'obertura. Podem assolir aquest potencial analític a partir de l'ús de la categoria festival.

\section{EXPERIENNCIES COMPARATIVES DE FESTIVALS}

El meta-missatge "això̀ és un festival" ens està dient que totes les manifestacions que es donen en aquest context són objecte de diversió i felicitar. Festival fa referència a un cert estil d'acció més que a formes específiques de conducta. Coubertin una vegada va escriure "si una persona em pregunta la fórmula per 'olimpialitzar-se', jo diria que la primera condició és estar alegre i feliç». En la meva observació etnogràfica, la presència o absència als carrers de carnestoltes i de tradicions de festivals populars, la distribució dels "llocs olímpics" en l'espai urbà, i les decisions del Comitè Organitzador, genera tot plegat grans diferències en com els participants olímpics reben l'experiència del festival. S'ha de tenir en compte que el festival de caire més popular durant els Jocs Olimpics no és gaire visible, sobretot per l'audiència que segueix l'esdeveniment per televisió. Algun medi de comunicació nacional, com va ser el cas de Brasil als Jocs Olímpics de Los Angeles, va contractar l'antropoleg professor Roberto DaMarta, expert en les celebracions de carnestoltes, per comentar aquests aspectes de festival popular. Ben al contrari, les cadenes americanes a Los Angeles van parar poca atenció en aquest tipus de festival. Tant en el primer cas com en el segon els espectadors televisius van estar allunyats 
de l'experiència del festival. Tal com ja he manifestat, es deuria de trobar una modalitat de festival de masses, però la paraula festival en si mateixa no contempla aquest significat. El festival en si no pot ésser televisat. Espectacle i festival estan, en el context olímpic, en oposició. Penso que a través de les característiques sociològiques i conductistes es pot entendre millor la noció de festival que jo proposo aquí, una noció que està molt propera a la noció de "carnavalitzación de Mikhail Bakhtin.

Festival es refereix paradigmàticament a tot allò que transpira en les places, parcs, carrers, autobusos, trens, bars, restaurants, hotels, en espais públics i privats, es refereix, doncs, a tot aquell espai on no es necessita bitllet d'entrada ni tenir un estatus determinat. Els espais de festival són més igualitaris i democràtics pel que fa a la presència física, a la participació i a la interacció voluntària i espontània.

Les distincions que per quiestió de rol poden existir entre actors $i$ audiències estan poc orientades vers una composició més igualitària de tots els "olimpics". Com a resultat, els codis de conducta són més flexibles i oberts a la innovació i el joc.

El festival és un "bricolatge» d'imatges que no apareixen unides per cap guió escrit, per cap esdeveniment central, per cap autoritat dominant ni per cap història ordenada amb principi, desenvolupament i desenllaç clar. La seva unitat rau en el talant, en l'atmosfera, en l'ethos difús i efervescent (en el sentit durkhemià), en la convivència, en la sociabilitat i en el plaer.

D'aquesta manera, el festival olímpic és allo que passa més fora que dintre, més als marges, a les periferies i als intersticis de la vida de la ciutat olímpica.

Malgrat això, l'ethos i la conducta del festival poden creuar ets marges, envair l'estadi, les zones d'entrenament de la Vila Olímpica, les sales comunitàries, les festes privades, els concerts i fins i tot els rituals d'obertura i clausura. Quan això passa, l'experiència del ritual està particularment marcada i pot arribar a amenaçar els àmbits estables del ritual, del joc i de l'espectacle.

Evidentment, tots els informes dels Comités Olímpics, a excepció del de Munic, insisteixen que els seus jocs varen ser celebrats en una atmosfera festiva. Perd aixd no sempre es correspon a la realitat. El nostre model, que té com a objectiu principal entendre el fet del festival, ens permet posar en ordre les observacions etnogràfiques dels diferents jocs de manera pormenoritzada per poder comparar.

El Festival de les Arts de Mont-real, per exemple, va ser petit, local i virtualment invisible per als visitants, així com també per als ciutadans autòctons. Reatment, aquest poc èmfasi del Comitè Organitzador de Mont-real va ser suficient per provocar un moviment de protesta dels activistes olímpics canadencs. 
Contràriament, el Festival de les Arts de Los Angeles va ser extens, amb una gran difusió i car. Malgrat això, estava virtualment finalitzat abans de començar. Es van fer actuacions molt cares enfocades a l'alta cultura internacional - tenint com a principal punt de referència Europa- orientat només a una petita comunitat artística i a l'èlit social. Així doncs, no es va fer res proper al festival popular. De nou, aquests fets provocaren crítiques al festival de Los Angeles. La crítica més recent emfasitza que per a poder parlar d'una veritable diversió festiva en els Jocs Olímpics, l'art ha de ser multicultural, les representacions han de tenir entrades assequibles, els espais on tenen Iloc han de ser oberts, defensant una ideologia d'obertura, i s'han de trencar els límits socials i de classe.

Les arts formals del festival de Seuil van seguir en certa manera el model de Los Angeles, convidant els artistes més famosos del món i fent pagar una entrada per veure'ls. Malgrat això, a través de les arts es va generar l'esperit del festival perquè es va convidar a grups culturalment $\mathrm{i}$ artísticament representatius de diferents països. A Setil així mateix, es preparà un espai on es donaven cita les obres esculròriques dels millors artistes de 80 països olímpics. Aquest parc olímpic de l'escultura va generar un espai de diversió pel festival popular i artístic: obert, igualitari, gratuït, amb menjar i beguda a l'aire lliure, i amb música i ball fins a altes hores de la matinada. Quan comparem els festivals de carrer dels diferents Jocs veiem imatges prou diferents. Com a regla general, podem dir que si les cultures amfitriones es caracteritzen per gaudir d'una tradició de convivència al carrer i de festival popular, aleshores aixd es tendirà a trastladar als Jocs Olímpics. Si aquesta característica no existeix, aleshores l'atenció de les autoritats i els responsables d'organització dels Jocs hatría de focalitzar els seus esforços cap aquest àmbit.

Mont-real va gaudir del festival més intens dels últims Jocs. Com Ciutat de Mèxic i Munic abans, el Canadà francès i catòlic harmonitzà els ritmes estacionals i els ritmes de calendari propis del medi rural amb la vida de la metròpoli. La cultura amfitriona tenia, en aquest cas, una rica tradició carnavalesca. Mont-real, la ciutat més europea de Nord-amèrica, també anomenada "el París de l'oest", va despendre poques energies i diners decorant la ciutat amb banderes de colors, animant les representacions al carrer i fent participar a la multitud perquè va ser la cultura local la que va donar ànim i vivacitat al festival.

Certament, hi van haver iniciatives del Comitè Organitzador de Mont.real per promoure experiències de festival. Però tant si l'efecte va ser intencionat com si no ho va ser, les tradicions dels habitants de Quebec i Mont. real varen influenciar les decisions del Comitè. Però el seu exit en generar un espai pel festival va ser el seu gran triomf. La ubicació en espais contingus dels quatre principals esdeveniments atletics, de la Vila Olímpica, dels dos 
camps de pràctiques oberts a la vista del públic, el parc, les diferents paradetes de menjar i beure al voltant de la plaça Central, asseguraven una contínua afluència de públic durant els dies i les nits de tot el període olímpic. Els Jocs Olímpics de Mont-real van gaudir d'un lloc central. Tant com a visitant o com a natiu, qualsevol sabia on trobar sempre moviment $i$ diversió.

Molt diferent és el cas de Los Angeles, una ciutat amb la reputació de ser la ciutat internacional dels plaers, que no va aconseguir que aquests plaers es realitzesin en el festival popular. El plaer en aquesta ciutat està associat a la indústria cinematogràfica de Hollywood. El festival s'organitza de forma tancada i orientat a minimirzar la interacció entre les persones. Segurament, van haver-hi moltes festes privades d'individus d'alta societat, empreses, de diplomàtics, etc. Peró l'accés restringit, la privacitat i els elevats preus es varen oposar a l'esperit del festival ja que separà la població privilegiada, de la massa de visitants que buscaven la celebració d'un festival popular.

En la simbòlica geografia de Los Angeles, les platges representaven el contrari de Hollywood: els espais oberts, els elements clau per construir un festival. Però les platges estaven massa liuny de qualsevol centre d'activitats olímpiques. Dins la ciutat, al mig de la geografia específicament olímpica no es van desenvolupar places centrals per donar vida al festival. Es varen dispersar les activitats olímpiques i amb això van aparèixer alguns problemes amb el transport públic. Tots aquests aspectes contribuïren a l'exit dels aspectes fiscals, administratius i de seguretat, però varen ser també els que impediren que tingués lloc el festival. El parc proper al Coliseum, un ampli espai obert, representava l'equivalent a la Plaça Olímpica de Mont-real. Però després de la cerimònia d'obertura el Coliseum va quedar buit durant més d'una setmana. Només les persones que anaven a veure boxa tenien una excusa per anar al parc del Coliseum. També es podien fer algunes compres pels voltants. La piscina olímpica no estava a molta distància però no era visible i s'havia de fer prou volta per arribar-hi. Quan es podia observar més moviment era quan la gent lluitava per trobar aparcament, agafar un autobús o un taxi.

Un dels misteris de Los Angeles era que essent una ciutat plena de tot tipus d'artistes de carrer, aquests van desapareixer durant la celebració dels Jocs. Per als observadors això va ser sorprenent.

En termes culturals, Los Angeles és una ciutat heterogènia i políglota amb extraordinaris recursos. Però en termes sòcio-econòmics, presenta pols extrems de riquesa i pobresa, una radical separació entre allò privat i allò públic, especialment amb l'allau d'immigrants d'origen hispà i asiàtic. Les èlits de Los Angeles parlen sovint que la seva ciutat s'està tornant una ciutat del tercer món, amenaçada per l'imperi del crim i la droga. Es tracta d'una cultura local presidida pel sentiment de seguretat personal, sentiment que no permet fomentar el sentit del festival popular. 
De fet el que succeeix quasi universalment sota el lema de la convivència olímpica no és un tumuit sinó una festa. Aquest aspecte hauria d'haver estat dinamitzat pel Comitè Organitzador, però la classe mitjana-alta i alta, que organitzava aquest esdeveniment, estava més preocupada per l'ordre públic que no pel festival popular. Aquests personatges del món dels negocis i de les èlits cíviqutes són probablement el grup social que menys entén la diferència entre "el desordre de carnaval" i uel perill criminal». A conseqüència de tot això, els festivals de carrer a Los Angeles pràcticament no van existir.

També varen ser gairebé inexistents a Seül però per diferents raons culturals. Les places centrals, els líocs de diversió $\mathrm{i}$ el transport van ser molt assequibles al públic. La curiositat entre els coreans i els visitants era recíproca. Però en una societat tan jeràrquica i personalista com la coreana cada festival havia de tenir un propietari. Els grans esdeveniments estaven patrocinats i es deixava poc espai per una celebració espontània, qüestió encara molt llunyana per la cultura coreana. Més encara, Corea és una societat sexualment reprimida, l'eros públic i la llibertat són associats als bàrbars occidentals. Fins i tot les mostres corporals dels atletes europeus en la Vila Olímpica eren motiu d'escàndol per als coreans. La llibertat en les relacions sexuals són una característica de la veritable festivitat de carnaval pels europeus, nord-americans, africans i llatinoamericans. Com a conseqüència, quasi sense excepció, els dos moments de festival popular a Seül varen ser iniciats pels estrangers. Els coreans observaven, però celebracions espontànies entre els uns i els altres no van tenir lloc.

Tornant als aspectes festius, podem reconèixer perquè no van pràcticament existir a la Vila Olímpica de Seül. Els coreans, actuant des dels seus patrons culturals, varen programar totes les representacions folklòriques i les festes per ballar i jugar. Evidentment l'alcohol estava prohibit i s'esperava que, respectant la disciplina olímpica, tots els atletes anessin a dormir d'hora. Tal com ja he mencionat, els balls es realizzaven al parc olímpic i en ocasions aconseguien fer-los molt animats. Però, malgrat aixo, la dura disciplina enfocada cap a una celebració formal, la impossibilitat d'adquirir alcohol i la poca presència dels coreans limitaven la seva intensitat. En definitiva, els atletes no coreans van trobar la Vila Olímpica confortable i servicial, però sense atractiu.

Los Angeles oferia una experiència completament diferent. La Vila Olímpica era més alegre que en cap dels últims Jocs Olímpics ja que es van establir forts lligams de companyonia $\mathrm{i}$, a més, moltes estrelles del rock van ser convidades a oferir recitals gratuïts. Segons l'estil americà-californià, les festes es perllongaven tota la nit i cada atleta havia de tenir cura de si mateix. Aquestes festes han estat considerades pels atletes com una Ilegenda dels Jocs Olimpics. La vida a la Vila Olímpica era tan atractiva que algunes delega- 
cions van tenir problemes per endur-se als seus atletes. Part de la raó per la qual el festival de Los Angeles va ser tan relativament pobre pel públic en general, era que els atletes poques vegades gosaven sortir del recinte per tal de barrejar-se amb la multitud per a divertir-se.

\section{RITUAL, FESTIVAL I ESPECTACLE}

Les relacions entre festival $i$ ritual en el marc dels comportaments $i$ de la meta-comunicació, ens mostren molt clarament les diferències comparatives entre les diverses cultures amfitriones. En el cas d'una representació ritual olímpica com és la torxa, les relacions tendeixen a ser complemetàries. A Mont-real la torxa olímpica va arribar electrònicament a Ottawa i no va ser seguida amb emoció pel públic. En canvi, en els recents Jocs, la torxa s'ha convertit en una imatge important de l'experiència festiva per la nació amfitriona. Les audiències estrangeres no estan gaire d'acord a atorgar-li tanta importància, de fet els diaris paren poca atenció al recorregut de la torxa i a la seva entrada a l'estadi durant la cerimònia d'obertura. Mentre la torxa circula per cada un dels indrets fortament escoltada, els ciutadans, en aquest peculiar lligam de comunitat, surten al carrer per veure-la. En ocasions desperta en ells mostres festives espontànies que entren a formar part de la celebració. Aquest procés es va desenvolupar amb una certa intensitat a Los Angeles. Es tractava de fer un veritable ritual en sentit durkhemià, tal com van fer els grecs. Per a Grècia i per a la gran audiència europea, el lliurament de la torxa olímpica és un fet que mereix ser recordat.

En els Jocs Olímpics de 1988, el disseny del relleu de la torxa va despertar un gran fervor, tal com ja havia succeìt a Canadà. A Corea no només les localitats de província, pobles i ciutats van celebrar el camí de la torxa, sinó que sovint es van organitzar festivals populars amb una oberta rivalitat política. Explícitament l'oposició política entre la cultura local i la cultura nacional, el festival de la gent i el festival de l'Estat, són ben coneguts a Europa però molt poc a America on el paper de l'Estat en els Jocs és mínim. Als Estats Units el relleu de la torxa, com els Jocs Olímpics en general, es considera que pertany exclusivament a la societat civil. Una altra diferència primordial, la trobem, com ja he comentat, en ta falta que Corea té d'una contrapartida entre festival i ritual, entre la diversió i el respecte com en la cultura americana i europea. En la lògica dominant d'Occident, emmarcar els fets com a ritual, demana solemnitat i reverència, en contrast amb l'espontaneïtat, les formes lliures i la diversió transgressora de les coses emmarcades com a festival. D'aquesta manera, per retornar al tòpic de les cerimònies obertes podem veure que les contradiccions interculturals estan consolidades i donen loc a malentesos, fins i tot en 
algun incident internacional. Aquest és el cas de l'entrada a la desfilada de nacions a Seül. Pels americans és molt dificil participar en una cerimónia d'obertura sistemàtica i consensuada com a ritual, amb matisos de religió i d'autoritarisme polític i anti-individualisme. Els americans van entrar espontàniament $\mathrm{i}$ desordenadament a l'estadi i això va representar una gran ofensa per els coreans, sobretot tenint en compte les circumstàncies polítiques. Varen interpretar les expressions americanes com a irrespetuoses per a la nació amfitriona. Per a Corea diversió $\mathrm{i}$ ordre no se separen, l'escàndol va ser molt sonat per ambdós països $\mathrm{i}$ els americans no van entendre mai perquè van ser convidats a disculpar-se en els més alts nivells. Després de tot, ells comentaven, no havien fet altra cosa que repetir el que ja havien fet a Los Angeles.

Feliçment aquests enfrontaments entre diferents contextos culturals i meta-comunicatius en les cerimònies d'obertura no són habituals, però n'hi ha d'altres que sí són molt corrents. Per exemple la intrusió d'accions propies del festival dins el ritual, la qual cosa pot arribar fins a ridiculitzar-lo. Malgrat que les cerimonies de Seit han estat qualificades com a brillants i creatives, la representació no va sorprendre.

A Mont-real, on les cerimònies d'obertura i clausura no van ser controvertides en ser completament indiferents, la conducta carnavalesca dels atletes va ser animada $i$ es va difondre un extraordinari festival a l'estadi que va durar quatre hores, després que ja hagués finalitzat la cerimònia formal. Durant aquesta cerimònia, els atletes i els espectadors, els responsables dels jocs i els ciutadans del carrer van trencar tots els límits que els separaven i van gaudir junts tota la nit. Cap festa d'aquest estil no va ser concebuda a Seül. A Los Angeles, la policia i els responsables del Comitè Organitzador varen dessallotjar l'estadi minuts després que les càmeres de televisió deixessin d'emetre. Malgrat això, abans de tancar la retransmissió, els organitzadors toleraren bastant el desordre carnavalesc dels atletes fins i tot quan aquest amenaçava superar el límit horari previst. Les controversies i diferències d'opinió generades per les cerimònies d'obertura i clausura dels Jocs Olímpics de Los Angeles, tant les que provenen d'Estats Units com les que apareixen arreu del món, posen de manifest com els contractes televisius no van contemplar la retransmissió d'una part dels Jocs, per exemple, una part del festival.

\section{LA DECISIO MES IMPORTANT DELS DISSENYADORS DE LES CERIMONIES OLIMPIQUES}

He intentat mostrar en les seccions anteriors que la decisió dels dissenyadors de les cerimònies ha de prendre's en funció del tipus de represen- 
tació cultural que ells volen produir. Gràcies a les investigacions comparatives, veiem que els diversos aspectes de les cetimònies poden ser entesos com a espectacle, ritual, festival o joc segons els contextos meta-comunicatius de les diferents cultures participants. Sobretot, els dissenyadors han d'escollir quins d'aquests codi meta-comunicatius desitgen fer servir per donar forma i emmarcar tota la representació. Els dissenyadors, en primer lloc, han de ser col-lectivament conscients que són ells els que tenen la decisio. En prendre-la, aquesta ha de respondre a la seva pròpia estructura cultural i de tradicions. També han de tenir la capacitat d'assumir les crítiques que els arriben sobre aquest determinat disseny.

Finalment, gràcies a un elevat grau d'autoconsciència i a l'estudi acurat d'altres Jocs Olímpics, poden anticipar les possibles conseqüències de la seva elecció per a aitres cultures participants. Els països visitants esperen ser tractats respectuosament i gaudir d'una cerimònia oberta on se sentin benvinguts com a participants actius.

A diferència del que passa a Europa, "la intel.ligèntsia" americana i la comunitat artística han tingut molt poc a veure amb "els olímpics". Per als americans, els Jocs Olímpics son explícitament un gran esdeveniment esportiu. Aquesta és la idea que domina tot el discurs sobre els Jocs Olímpics i el ritual només resta per a les cerimònies de victòria. El gènere més freqüentment utilitzat per a les cerimònies d'obertura i clausura és l'espectacle i les seves modalitats com són ara el «show», la diversió, la representació a l'aire Iliure. Els adjectius que se solen utilitzar per descriure-les tenen un marcat accent d'emoció: "color", "moviment", "impresionant", "bonic", "emocionant", etc. El domini del joc i l'espectacle no és d'estranyar, ja que ambdós conceptes són molt familiars per als americans. Joc i espectacle també van ser les categories en les quals el Comitè Organitzador de los Angeles va centrar la seva arenció. Només alguns dels membres d'aquest Comitè van reconèixer que segons cada una de les nacions l'esdeveniment olímpic podia ser entès de maneres diferents, com passa a Europa. Malgrat això, els organitzadors de Los Angeles I984 van voler mostrar la ciutat com la capital mundial de la diversió.

Els coreans van escollir que la cobertura d'aquestes cerimònies fos el ritual, és a dir, el sagrat ritual olímpic. Per exemple, la torxa olímpica a Corea representava el foc sagrat reverentment dedicat. Es tractava d'una representació narrativa profunda de la cultura nacional coreana. A Los Angeles, les cerimònies estaven determinades, o bé s'assumia que fossin un espectacle o bé un gran entreteniment. El disseny i la producció de les cerimònies es va reduir a decidir si s'assumia que fossin un espectacle o bé un gran entreteniment, a decidir entre les propostes de "Walt Disney" i les del productor cinematogràfic David Wolper, les quals finalment van ser les escollides pel Comitè. 
Aparentment, el Comitè Organitzador de Los Angeles mai no va convidat cap professor universitari $i$, malgrat que alguns artistes americans foren més tard seleccionats, les seves contribucions no van ser incloses en els escenaris olímpics més importants. Hi havia algunes excepcions; però, en general, l'aportacio de les arts americanes i de les comunitats intel.lectuals en aquestes cerimònies van ser mínimes i sempre sota el domini de la indústria de la diversió centrada en les pel.lícules, la televisió, l'animació en els parcs i l'imperi de l'espectacle. Podem dir que els dissenyadors de les cerimònies del Comitè Organitzador de Los Angeles no es van proposar res més que un espectacle de diversió per a la classe alta, un espectacle de televisió. Només alguns d'ells van arribar a entendre per què les seves produccions generaven tanta remor en tot el món. Darrera de la seva ignorància sobre el Moviment Olímpic, que també existeix més enllà dels Estats Units, i del seu desinterès per estudiar altres cultures, haurien pogut reaccionar davant les seves produccions, els dissenyadors de les cerimònies van escollir ignorar que la meta-comunicació de l'espectacle inspira no només sorpresa sinó també matisos morals.

Atès el marcat contrast entre Los Angeles 1984 i Seül 1988, les audiències de tot el món estan ara esperant la decisió de com serà el contex dominant de les cerimònies olimpiques de Barcelona: espectacle d'entreteniment, ritual o qualsevol altre. Persones alienes a l'organització dels Jocs, com és el meu cas, no coneixem prou bé Espanya, Catalunya, Barcelona i el Comitè Organitzador d'aquesta ciutat per poder predir quin serà el resultat.

\section{EL MON CAP A BARCELONA, BARCELONA CAP AL MON}

Els estudiosos dels Jocs Olímpics estem actualment esperant analitzar els criteris pels quals han optat els dissenyadors i les autoritats de Barcelona.

Es comenta àmpliament que aquestes cerimònies emfasitzaran les relacions dins la nova Europa del 1992 i, d'una manera més específica, el paper d'Espanya en la perspectiva d'una Europa unida. Les cerimònies tenen també la responsabilitat de mostrar quines són les relacions entre Espanya i Cata. lunya, $\mathrm{i}$ entre aquesta última i les diferents formacions polítiques i ideològiques, no només del Principat sinó més concretament de Barcelona.

Penso que l'elecció del Comitè Organitzador de Barcelona sobre el tipus de cerimònies que s'han de celebrar té dues alternatives possibles: o bé els dissenyadors del $\mathrm{COOB}$ estan intentant fer un treball de significat històricoartístic capaç d'inspirar reflexions per propers anys, tal com varen fer a Seü;; o bé, estan buscant una diversió agradable i entretinguda $i$, a la vegada, un espectacle televisiu que només tindrà ressò en les seves propies ments i en les del petit grup defs investigadors internacionals de les olimpíades. 